\title{
信息技术在水利工程建设管理中的应用
}

杨 斌

临泉县洪河河道管理所, 安徽临泉 236400

[摘要]在最近的几年时间里, 我国综合国力得到了全面的提升, 在这个过程中使得各类资源被大量的开发利用, 从而导致资 源匮乏的问题越发的凸显出来，尤其是水资源的紧缺的问题十分的严重。为了有效的缓解当前水资源遗乏的问题，我国越发 的重视水利工程建设工作。在水利工程中水利工程建设管理工作的作用可以说是非常重要的, 高水平的管理工作能够有效的 提升水利工程建设工作的效率和水平, 保证各项工作能够按照既定的计划按部就班的进行。将信息技术切实的运用到水利工 程建设管理工作之中, 可以提高水利工程建设工作的整体水平, 并且可以推动水利工程建设管理信息化水平的提高, 确保管 理工作能够实现既定的科学性的目标。

[关键词]信息技术; 水利工程; 建设管理

DOI: $10.33142 /$ hst.v3i5.2645 中图分类号: TV51 文献标识码：A

\section{Application of Information Technology in Water Conservancy Project Construction Management}

YANG Bin

Linquan Honghe River Channel Management Office, Linquan, Anhui, 236400, China

\begin{abstract}
In recent years, Chinese comprehensive national strength has been comprehensively improved. In this process, a large number of resources have been developed and utilized, resulting in the problem of resource shortage becoming more and more prominent, especially the shortage of water resources is very serious. In order to effectively alleviate the current lack of water resources, China has paid more and more attention to the construction of water conservancy projects. In water conservancy project, the role of water conservancy project construction management work can be said to be very important, high-level management can effectively improve the efficiency and level of water conservancy project construction work and ensure that the work can be carried out step by step according to established plan. The practical application of information technology in water conservancy project construction management can improve the overall level of water conservancy project construction work and promote the improvement of water conservancy project construction management information level, so as to ensure that the management work can achieve the established scientific objectives.
\end{abstract}

Keywords: information technology; water conservancy project; construction management

\section{引言}

因为水利工程建设工作牵涉到的层面较多, 这样就会对管理工作形成诸多的阻碍, 要想保证水利工程建设工作的 有序开展, 最为有效的方法就是将信息技术切实的引用到水利工程建设管理工作之中, 促进水利工程建设管理机制整 体水平不断提高。其次, 在组织开展水利工程建设管理工作的时候, 要针对性的设立管理标准, 并且要将工程质量看 做是管理工作的基础, 安排专人对工程建设管理工作进行全面的监督。再有, 借助信息技术能够在综合各方面实际情 况的基础上，挑选恰当的施工材料，并提升施工材料的利用效率。利用信息技术能够对水利工程建设过程中形成的所 有信息数据进行统一收集分析，从而为水利工程建设工作效率的提升创造良好的基础。

\section{1 信息技术在水利工程建设管理中应用的意义}

将信息系统切实的运用到实践工作之中, 能够对工程建设技术相关规范制度以及实践落实加以明确 ${ }^{[1]}$ 。如果信息技 术的发展与目标保持良好的统一的时候, 在针对水利工程特点和经济性加以综合分析的基础上, 高效的借助信息系统, 可以有效的提升信息利用的效率。水利工程项目的主要作用就是对覆盖的区域的水资源进行合理的调控，水利工程管 理的核心就是将所有分支工程进行整合, 并实现合理的安排。水利工程与社会经济和民众生活息息相关, 所以水利工 程项目务必要对各项因素加以综合分析, 并编制出切实可行的工程方案。水利工程管理其实质是借助相关职能部门的 权限参与到工程规划之中, 最为重要的就是能够借助到外部经济层面的支持。水利工程项目不但与社会经济发展存在 
关联, 并且对于生态环境的保护也具有非常重要的辅助作用。水利工程信息化的内涵见图 1 。

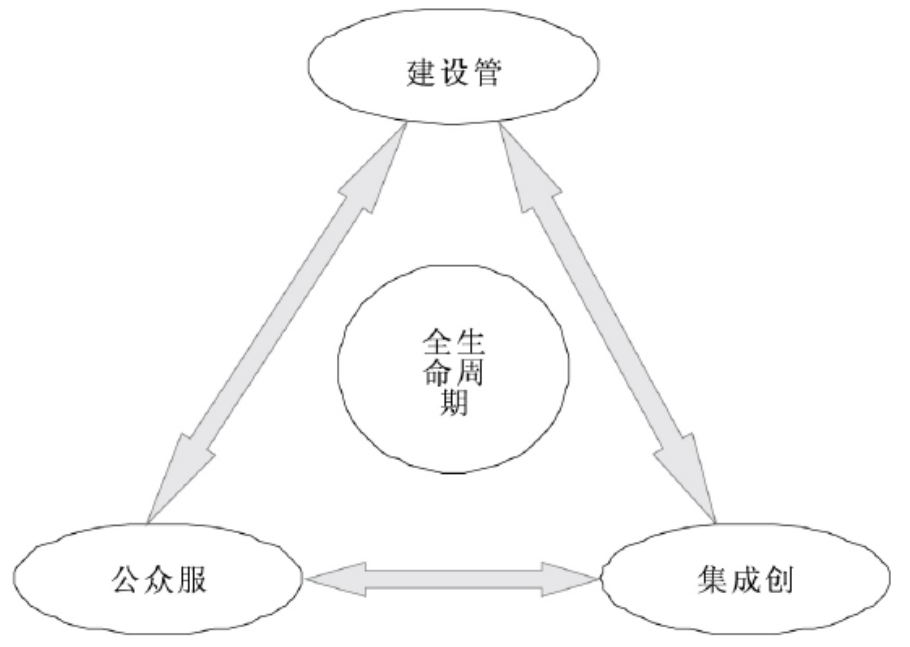

图 1 水利工程信息化的内涵图

\section{1 有助于先进管理模式的形成}

在科学技术飞速发展的影响下, 使得我信息化技术被大范围的引用到了水利工程建设管理工作之中, 并已经形成 了先进的管理模式，极大的提升了各项工作的整体水平和效率，为各项工作的有序开展创造了良好的基础 ${ }^{[2]}$ 。

\section{2 有助于建设管理效率的提升}

就水利工程来说最为突出的特征就是综合性强、系统性强, 水利工程建设管理工作涉及到对信息的收集、综合分 析、存储、运用等多项工作, 并且需要对各个部门的工作进行统一的调控, 有效的促进工作效率的不断提升。

\section{2 水利工程建设信息化管理存在的问题}

\section{1 缺乏水利工程信息化管理观念}

就现如今水利工程信息化管理工作实际情况来说, 最为突出的问题就是不具备良好的信息化管理理念。在我国部 分地区自爱水利工程建设工作中, 因为施工上层管理工作人员对于信息化管理缺少正确的认识, 所以导致水利工程信 息化管理工作无法有效的发展。很多水利工程领导人员因为对信息机制了解较少，所以单纯的认为利用信息技术就是 为了施工过程中工作效率的提升, 其效果还不如传统管理方式。正是因为这种错误的观念的存在, 所以对水利工程信 息化管理工作的发展形成了诸多的阻碍 ${ }^{[3]}$ 。

\section{2 信息化水利工程建设形式化严重}

当前, 我国水利工程建设形式化问题十分的突出, 并且没有切实的利用信息化的方法, 这样就会对水利工程建设 管理工作的落实形成一定的限制。虽然很多的水利工程建设管理工作都已经实现了信息化操作, 或者已经创设了网络 化的管理平台来对水利工程建设管理工作给予了辅助, 但是不得不说的是, 在实际工作开展中, 人为操作管理模式并 没有被信息化的管理模式所取代，在部分简单的项目之中，为了提升工作的效率，管理工作人员通常都只会结合自身 的实践经验来对工作情况进行预判，而不会借助信息技术来对各项工作加以合理的安排。

\section{3 水利工程建设管理中信息技术的应用}

\section{1 信息技术在数据采集工作中的应用}

一般情况下，在正式开展水利工程建设工作之前，施工单位往往都会对工程涉及到的各项信息数据进行统计，这 样做的目的就是为后续各项工作计划的制定给予良好的辅助。但是, 数据采集需要综合工程所处地区各方面情况来加 以综合深入的分析研究。在前期实地勘察工作的开展中，GPS 技术的使用效率较高，借助这项技术能够确保信息数据收 集的准确性, 并且这项技术在环境分析方面具有非常重要的作用, 可以从根本上保证水利工程施工工作的整体水平和 效率 ${ }^{[4]}$ 。 


\section{2 信息技术在工程绘图中的应用}

就一个完整的水利工程项目来说, 工程绘图工作的作用是非常重要的, 绘图工作的效率和效果往往都会对工程施 工质量和施工效率存在一定的关联。因为水利工程的绘图能够从整体上将工程结构呈现出来, 所以在落实绘图工作时 候务必要对其中涉及到的各项信息数据的准确性加以把控, 这样才能确保整个绘图的质量和效果。就以往工程绘图来 说, 通常需要持续较长的时间, 这样就会导致后期工程施工周期的紧张, 并且绘图的制作通常都是单纯的依赖人工操 作完成, 所以绘图的准确性无法加以根本保证。如果自爱工程绘图中能够高效的运用信息技术, 那么可以从根本上对 绘图的准确性加以保证, 并且借助信息技术进行绘图, 能够从根本上保证绘图各项信息数据的准确性, 从而为后续各 项工作的有序高效的开展创造良好的基础。

\section{3 施工管理中的水利工程应用}

由于水利工程在施工的过程中所涉及的范围较广, 其施工环节较为复杂, 因此施工管理方面也具有一定的难度, 而 且施工管理工作所涉及的环节较多, 主要包括施工设备的管理、施工各环节的管理、施工人员的管理等, 如果在管理的 过程中出现问题, 那么就会对施工过程留下安全隐患, 甚至导致严重的后果。将信息技术应用到施工管理工作中, 能够 实现施工管理的全面管理。例如, 施工管理中将信息技术进行合理的应用, 能够对不同的施工环节进行明确的分类, 并 能够为管理工作建立完善的管理信息数据系统提供帮助。另外, 在进行施工设备的管理过程中, 信息技术还能够对设备 的各种信息进行全面性的统计, 并完成详细的记录, 而且还能够实现信息的共享, 为施工人员提供正确的引导 ${ }^{\left[{ }^{5}\right]}$ 。

\section{4 信息技术在水利工程验收阶段的应用}

水利工程完工验收工作也是非常重要的, 在整个工作中需要针对工程施工质量以及多个方面加以整体验收, 在这 个过程中切实的运用信息技术，可以有效的提高验收工作的效率和效果，并且能够促进管理工作整体水平的提升。

\section{结语}

综合以上阐述我们总结出, 在现如今科学技术飞速发展的影响下, 信息技术水平得到了全面的发展, 将信息技术 恰当的运用到水利工程建设管理工作, 其实质就是借助网络技术、数据库技术以及多项专业技术来对管理工作加以辅 助。要想将信息技术在水利工程建设管理工作中的作用充分的发挥出来, 那么最为重要的就是需要有效的提升管理工 作人员对信息管理系统的认知, 并且要大范围的运用最前沿的管理机械, 掌握先进的管理技巧, 创设完善的管理机制, 并且要加强各个部门之间的沟通和联系, 从而保证管理工作整体水平的提高。

\section{[参考文献]}

[1]保庭潇.信息技术在水利工程管理中的应用研究 [J]. 科技风, 2020 (15) : 194 .

[2]张高.信息技术在水利工程建设管理中的应用 $[\mathrm{J}]$.中国高新科技, 2019(17): 77-79.

[3] 马宾, 黄振华. 水利工程管理中信息技术的实践应用 [J]. 黑龙江水利科技, 2017, 45(05): 147-149.

[4]林代桂.试论信息技术在水利工程建设管理中的运用 [J]. 江西建材, 2016 (06) : 140-145.

[5]于田龙. 信息技术在水利工程建设管理中应用分析 $[\mathrm{J}]$. 科技创新与应用, 2015 (22) : 206 .

作者简介: 杨斌( 1977.3.18-), 男, 安徽省临泉县城关街道办, 汉族, 大专学历, 工作方向: 安徽省临泉县洪河河道 管理所。 